\title{
Preparation of Mesoporous Silica-Supported Palladium Catalysts for Biofuel Upgrade
}

\author{
Ling Fei, Harvind Kumar Reddy, Joshua Hill, Qianglu Lin, Bin Yuan, Yun Xu, \\ Peter Dailey, Shuguang Deng, and Hongmei Luo
}

Department of Chemical Engineering, New Mexico State University, Las Cruces, NM 88003, USA

Correspondence should be addressed to Hongmei Luo, hluo@nmsu.edu

Received 15 February 2012; Accepted 29 March 2012

Academic Editor: Guifu Zou

Copyright $\odot 2012$ Ling Fei et al. This is an open access article distributed under the Creative Commons Attribution License, which permits unrestricted use, distribution, and reproduction in any medium, provided the original work is properly cited.

\begin{abstract}
We report the preparation of two hydrocracking catalysts $\mathrm{Pd} / \mathrm{CoMoO} /$ silica and $\mathrm{Pd} / \mathrm{CNTs} / \mathrm{CoMoO}_{4} /$ silica $(\mathrm{CNTs}$, carbon nanotubes). The structure, morphologies, composition, and thermal stability of catalysts were studied by X-ray diffraction (XRD), scanning electron microscopy (SEM), Raman spectroscopy, transmission electron microscopy (TEM), energy-dispersive X-ray (EDX), and thermogravimetric analysis (TGA). The catalyst activity was measured in a Parr reactor with camelina fatty acid methyl esters (FAMEs) as the feed. The analysis shows that the palladium nanoparticles have been incorporated onto mesoporous silica in $\mathrm{Pd} / \mathrm{CoMoO} /$ silica or on the $\mathrm{CNTs}$ surface in $\mathrm{Pd} / \mathrm{CNTs} / \mathrm{CoMoO}{ }_{4} /$ silica catalysts. The different combinations of metals and supports have selective control cracking on heavy hydrocarbons.
\end{abstract}

\section{Introduction}

Large expansion of the human population has caused a sharp increase in energy consumption resulting in a rapid decrease in the earth's fossil reserves [1-6]. The combustion of fossil fuels releases a large amount of $\mathrm{CO}_{2}$ and has caused serious climate changes and other global problems [6]. Biodiesel (fatty acid methyl esters, FAMEs), derived from renewable sources like biomass and animal fats, has been considered as clean, renewable, sustainable alternatives to fossil fuels and has received increasing attention as transportation fuel. A problem with transesterification products is that they are mainly composed of ester, which shows limited compatibility with petroleum-derived fuel because of high oxygen content, lower thermal stability, and poor cold flow properties $[6,7]$. Posttreatment processes like hydrocracking or pyrolysis with hydroreforming must then be applied to eliminate oxygen and shorten carbon chains. These processes change the transesterified product to resemble conventional fuel derived from fossil sources [5]. This paper focuses on the preparation of catalysts for the hydrocracking process, which is one of the key processes to convert heavy feedstocks to high-quality fuels like gasoline and middle distillate [8-15].
The role and importance of catalysts in the hydrocracking processes has been intensely studied [14-27]. Generally, the hydrocracking catalysts composed of noble metals or transition metals paired with a mesoporous support have dual functions in the reaction process. These are (a) cracking C-C bonds from high-molecular weight hydrocarbons and (b) hydrogenating the unsaturated hydrocarbons formed in the cracking steps and/or were already present in the feedstock $[17,18]$. The most conventional catalysts are $\mathrm{NiW}$, NiMo, and CoMo bimetallic paired on a number of supports, including zeolite, silica-alumina, and alumina [1922]. Recently, Pd-based catalysts have also been widely used due to their high activity on hydrocracking sulfur-free heavy hydrocarbons [24-27]. Besides the catalyst compositions, it was also found that the selectivity of a catalyst highly depends on the support materials and dispersion of metals in the supports $[16,26]$. Due to specific interaction between metals and supports, different supports can result in distinctive results.

Carbon nanotubes (CNTs), one of the most important materials since it was discovered, have been widely applied to composite materials, lithium ion batteries, supercapacitors, microelectronics, probe microscopy, and miscellaneous 
energy storage $[28,29]$. Its high accessible surface area and chemical stability also make it a promising candidate for use as a catalyst support. Metal-decorated CNTs applied in the field of catalysis have shown interesting catalytic properties and outstanding performance. For example, PdCNT has been proved to be very efficient in catalyzing Suzuki-Miyaura couplings [30, 31]. Inspired by previous reports, we are interested in designing $\mathrm{Pd} / \mathrm{CoMoO}_{4} /$ silica and $\mathrm{Pd} / \mathrm{CNTs} / \mathrm{CoMoO}_{4} /$ silica catalyst systems for hydrocracking. On the one hand, $\mathrm{Pd}$ and $\mathrm{CoMoO}_{4}$ are catalysts for hydrocracking; on the other, the CoMo bimetallic supported on silica has been reported as good catalyst for growing CNTs $[32,33]$ and has also proven to be effective on hydrodesulphurization, which helps lower the chance of sulfur poisoning the Pd catalyst $[34,35]$.

Herein, we report the synthesis of two catalysts: Pd directly loaded on a silica support and Pd loaded on CNTs. The performance of the catalytic production of jet fuel range carbon-chained molecules (C8-C16) from camelina fatty acid methyl esters (FAMEs) shows that the two catalysts have good selectivity in a hydrocracking test.

\section{Experimental Procedures}

2.1. $\mathrm{CoMoO}_{4}$ Catalyst Prepared by Polymer-Assisted Solution Method. $0.291 \mathrm{~g}$ Co $\left(\mathrm{NO}_{3}\right)_{2} \cdot 6 \mathrm{H}_{2} \mathrm{O}$ and $0.353 \mathrm{~g}$ $\left(\mathrm{NH}_{4}\right)_{6} \mathrm{Mo}_{7} \mathrm{O}_{24} \cdot 4 \mathrm{H}_{2} \mathrm{O}$ were dissolved together. $0.808 \mathrm{~g}$ ethylenediaminetetraacetic acid (EDTA) and $1.62 \mathrm{~g}$ polyethyleneimine (PEI, $50 \mathrm{wt} \%$, from Sigma-Aldrich, average $\left.M_{n} \sim 60,000, M_{n} \sim 750,000\right)$ were dissolved in about $35 \mathrm{~mL} \mathrm{H}_{2} \mathrm{O}$. The previous two solutions were mixed under magnetic stirring for $10 \mathrm{~min}$. The solution was heated at $600^{\circ} \mathrm{C}$ in air for 1 hour with a ramping rate of $1^{\circ} \mathrm{C} / \mathrm{min}$.

2.2. $\mathrm{CoMoO}_{4}$ Catalyst Incorporated into Mesoporous Silica $\left(\mathrm{CoMoO}_{4} /\right.$ Silica $) .0 .06 \mathrm{~g} \mathrm{CoMoO}_{4}$ catalyst was dispersed in deionized water to form a suspension, into which $1 \mathrm{~g}$ silica (70-230 mesh, $60 \AA$ ) was added. The suspension was aged at room temperature overnight and then heated at $600^{\circ} \mathrm{C}$ in air for 1 hour with a ramp rate of $1{ }^{\circ} \mathrm{C} / \mathrm{min}\left(6 \mathrm{wt} \% \mathrm{CoMoO}_{4}\right.$ loading).

2.3. $\mathrm{Pd} / \mathrm{CoMoO}_{4} /$ Silica Catalyst by the Reduction of $\mathrm{Pd}$. $0.108 \mathrm{~g} \mathrm{Pd}\left(\mathrm{NO}_{3}\right)_{2} \cdot 2 \mathrm{H}_{2} \mathrm{O}, 0.294 \mathrm{~g}$ sodium citrate, and $0.198 \mathrm{~g}$ sodium ascorbate were each dissolved in water in 3 separate tubes. Deionized water was added to $1.56 \mathrm{~g} \mathrm{CoMoO}_{4} /$ silica, in which $\mathrm{Pd}\left(\mathrm{NO}_{3}\right)_{2}$ solution was then added under magnetic stirring. Then sodium citrate solution was added to the mixture. After another $10 \mathrm{~min}$, sodium ascorbate was added. The final product was obtained after stirring the mixture solution for $30 \mathrm{~min}$ and then drying at $90^{\circ} \mathrm{C}$ overnight (5 wt $\%$ Pd loading).

2.4. $\mathrm{Pd} / \mathrm{CNTs} / \mathrm{CoMoO}_{4} /$ Silica Catalyst. All steps remained the same in the preparation of $\mathrm{Pd} / \mathrm{CoMoO}_{4} /$ silica, except that CNTs were grown before the reduction of Pd. CNTs were grown by chemical vapor deposition $(\mathrm{CVD})$ : the $\mathrm{CoMoO}_{4} /$ silica was reduced in $\mathrm{H}_{2}$ flow at $500^{\circ} \mathrm{C}$ for 0.5 hours. The flow was then changed to He for 0.5 hours. Next, the $\mathrm{CoMoO}_{4} /$ silica was exposed to a flow of pure $\mathrm{C}_{2} \mathrm{H}_{2}$ for 1 hour. Finally, the furnace was cooled to room temperature.

2.5. Characterization. The phase and structure of the catalysts were characterized by X-ray diffraction (XRD) using $\mathrm{Cu}$ radiation on a powder Scintag XRD operating at $45 \mathrm{kV}$ and $36 \mathrm{~mA}$. The morphology, microstructure, and composition were investigated by $\mathrm{H}-7650$ transmission electron microscopy (TEM) and S-3400 N II scanning electron microscope equipped with energy-dispersive X-ray (EDX). Raman spectroscopy was performed using $632.8 \mathrm{~nm}(1.96 \mathrm{eV})$ laser excitation. Thermogravimetric analysis (TGA) was performed by Pyris 1 TGA. The Brunauer-Emmett-Teller (BET) specific surface area of the samples was determined by an ASAP 2010 using the standard $\mathrm{N}_{2}$ adsorption and desorption isotherm measurements at $77 \mathrm{~K}$.

The hydrocracking of camelina biodiesel reaction was carried out in a PARR 4593 stainless steel bench top reactor accompanied by a 4843 controller unit (Parr Instrument Company). Feedstock camelina fatty acid methyl esters (FAMEs) were fed to the reactor along with $10 \mathrm{wt} \%$ of catalyst. The reactor was purged with nitrogen twice to remove oxygen present in the reactor. The temperature was then raised up to $300^{\circ} \mathrm{C}$ in $25 \mathrm{~min}$, and the reaction was carried out for 2 hours. Hydrogen was supplied to the reactor semicontinuously at 450 psi pressure during entire course of reaction, as it also acted as a carrier gas for removing $\mathrm{CO}_{2}$ and $\mathrm{H}_{2} \mathrm{O}$ formed during the reaction. After completion of the reaction, the reactor was cooled down to room temperature and the product sample was collected. The crude processed fuel was then analyzed with gas chromatography-mass spectrometry (GC-MS) system composed of an Agilent 5975 C MSD and an Agilent 7890 A GC equipped with a capillary column (DB-23, $60 \mathrm{~m} \times 250 \mathrm{~mm} \times 0.15 \mathrm{~mm}$ nominal).

\section{Results and Discussion}

A recent report on bimetallic catalysts pointed out that chemically bonded bimetallic catalysts have a synergistic effect in reactions and that catalysts with more than two metal substances were mostly prepared by physical mixture method [23]. The method used here to prepare $\mathrm{CoMoO}_{4}$ is polymer-assisted chemical solution method $[36,37]$. In the solution, soluble polymers bind to the metal ions to prevent premature precipitation. The calcination removing of polymers leads to high surface area sponge-like oxides. $\mathrm{CoMoO}_{4}$ was then incorporated into silica gel by incipient wetness impregnation. Subsequently, $\mathrm{Pd} / \mathrm{CoMoO}_{4} /$ silica was obtained by the addition of $\mathrm{Pd}\left(\mathrm{NO}_{3}\right)_{2}$ precursor and a reducing agent in $\mathrm{CoMoO}_{4} /$ silica [38]. The second catalyst, $\mathrm{Pd} /$ $\mathrm{CoMoO}_{4} / \mathrm{CNT}$ s/silica, was prepared in the same procedure, except that CNTs were grown before the Pd-reducing step.

Figure 1(a) shows the XRD pattern of $\mathrm{CoMoO}_{4}$. All the peaks can be indexed to $\mathrm{CoMoO}_{4}$ (JCPDS, number 21-0868). By applying Scherrer's equation in (1) on three main peaks, the average grain size calculated is around $29 \mathrm{~nm}$ :

$$
D=\frac{0.89 \lambda}{\beta \cos \theta}
$$




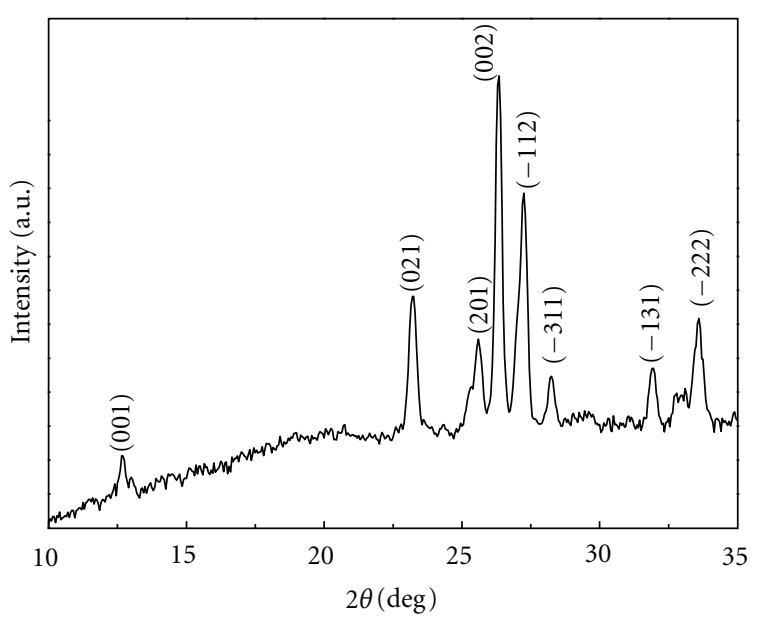

(a)

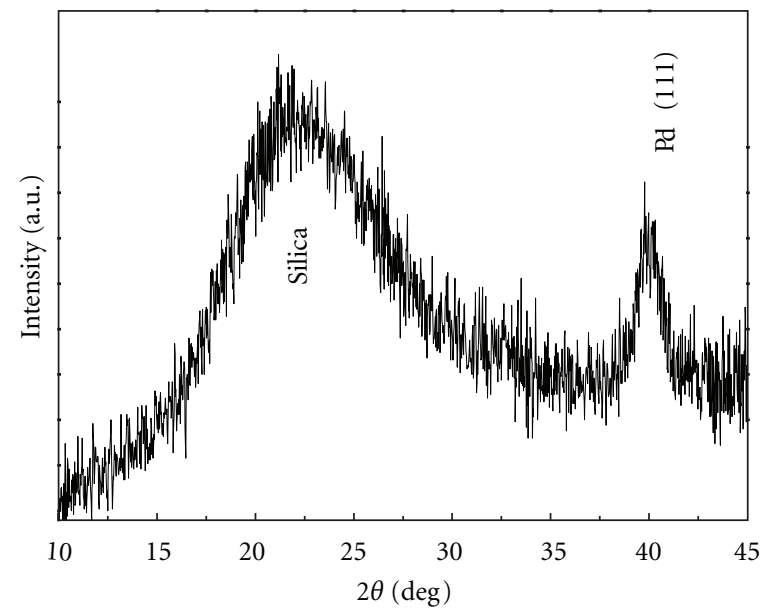

(c)

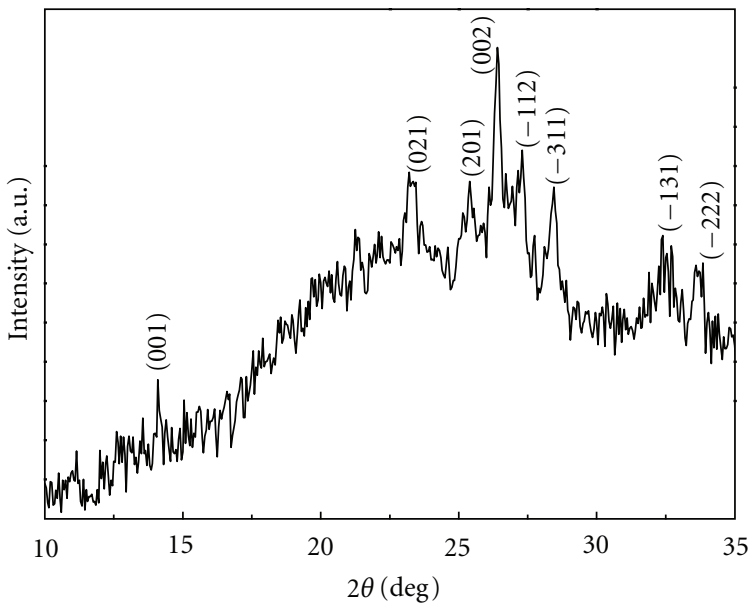

(b)

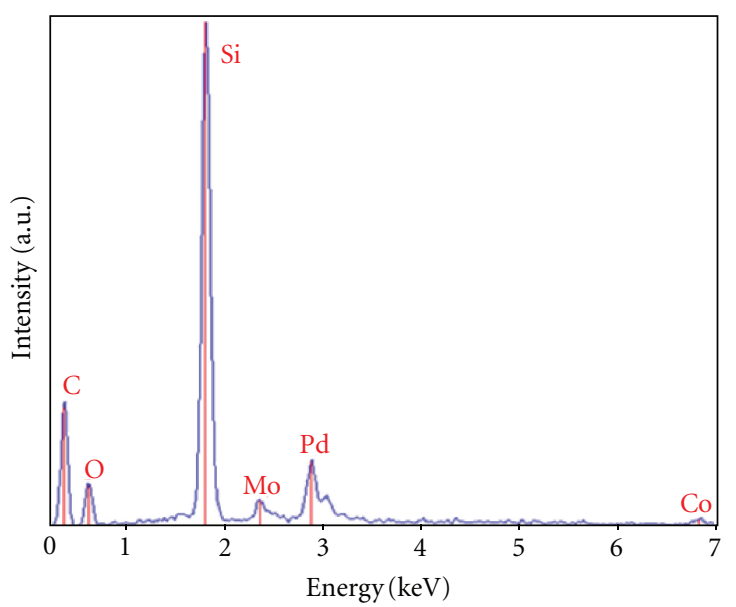

(d)

FIgure 1: XRD patterns of $\mathrm{CoMoO}_{4}(\mathrm{a}), \mathrm{CoMoO}_{4} /$ silica (b), $\mathrm{Pd} / \mathrm{CoMoO}_{4} /$ silica (c), and $\mathrm{EDX}$ of $\mathrm{Pd} / \mathrm{CoMoO}_{4} /$ silica catalysts (d).

where $D$ is the average grain size, factor 0.89 is characteristic of spherical objects, $\lambda$ is the X-ray wavelength, $\beta$ is the fullwidth at half-maximum of the diffraction peaks, and $\theta$ is the diffraction peak angle, respectively.

Figure 1(b) shows $6 \mathrm{wt} \% \mathrm{CoMoO}_{4}$ incorporated into amorphous mesoporous silica. Only several main peaks of $\mathrm{CoMoO}_{4}$ remain as compared with Figure 1 (a) due to its small ratio in silica. In Figure $1(\mathrm{c}), 5 \mathrm{wt} \%$ palladium is reduced and incorporated into the $\mathrm{CoMoO}_{4} /$ silica. The observed $\mathrm{Pd}(111)$ peak indicates that $\mathrm{Pd}\left(\mathrm{NO}_{3}\right)_{2}$ was successfully reduced at room temperature. Since the intensities of palladium and silica background are stronger than $\mathrm{CoMoO}_{4}$ peaks, it is hard to identify $\mathrm{CoMoO}_{4}$ peaks here. In Figure 1(d), the EDX analysis confirms the presence of Co and $\mathrm{Mo}$ in the catalysts with the $\mathrm{C}$ peak from the carbon grid. The XRD and EDX analyses show that the $\mathrm{Pd} / \mathrm{CoMoO}$ / silica catalysts have been synthesized successfully step by step.

For the $\mathrm{Pd} / \mathrm{CoMoO}_{4} / \mathrm{CNTs} /$ silica catalyst, which can be seen in Figure 2(a), the SEM image shows that the catalyst surface is well covered by CNTs, which is consistent with a sharp decrease in BET surface area of the catalyst after
CNT growth. The BET surface area of $\mathrm{Pd} / \mathrm{CoMoO}_{4} /$ silica is $243 \mathrm{~m}^{2} / \mathrm{g}$, while $\mathrm{Pd} / \mathrm{CNTs} / \mathrm{CoMoO}_{4} /$ silica is only $8 \mathrm{~m}^{2} / \mathrm{g}$. Compared with mesoporous silica with a surface area of $500 \mathrm{~m}^{2} / \mathrm{g}$, the lower surface area of $\mathrm{Pd} / \mathrm{CoMoO}_{4} / \mathrm{silica}$ is attributed to the impregnation of $\mathrm{CoMoO}_{4}$ and $\mathrm{Pd}$; the extremely lower surface area of $\mathrm{Pd} / \mathrm{CNTs} / \mathrm{CoMoO} / /$ silica is due to the coverage of CNTs. In the Raman spectrum shown in Figure 2(b), D band $\left(\sim 1330 \mathrm{~cm}^{-1}\right)$ and $G$ band $\left(\sim 1595 \mathrm{~cm}^{-1}\right)$ indicate the presence of carbon material. High $D$ band indicates that lots of defects existed in the CNTs, which corresponded to TEM images (Figure 3(c)) which show that the surface of CNT is in fact not smooth. From TEM images in Figure 3, we can also see that the CNTs are multiwalled with a diameter as large as $150 \mathrm{~nm}$. The rough surface of CNTs is amorphous and good for palladium embedding. As can be confirmed in Figures 3(d), 3(e), and $3(\mathrm{f})$ palladium particles are almost evenly embedded onto the surface of CNTs. Therefore, even though the BET surface of the $\mathrm{Pd} / \mathrm{CoMoO}_{4} / \mathrm{CNTs} /$ silica is low, the catalytic reaction surface is actually quite large, taking place on the surface of CNTs and guaranteeing the catalytic effectiveness. 




(a)

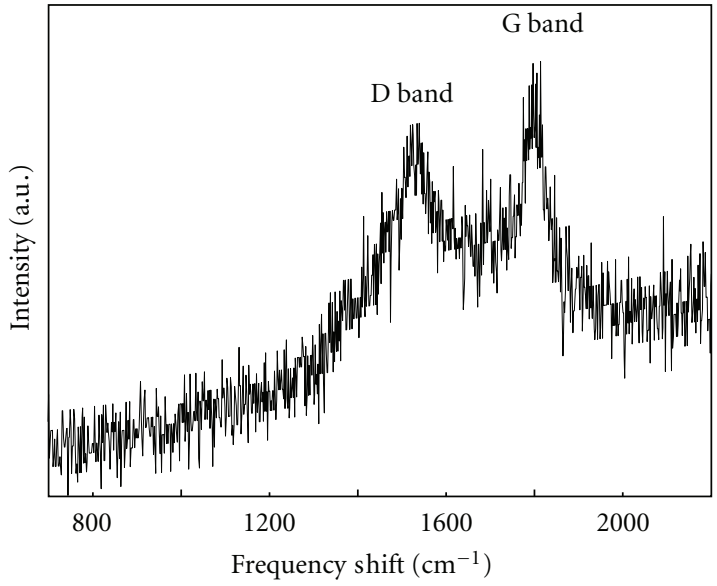

(b)

Figure 2: SEM image (a) and Raman spectrum (b) of Pd/CNTs/CoMoO$/$ silica catalysts.


Figure 3: TEM images of CNTs/CoMoO $4 /$ silica (a, b, and c) and Pd/CNTs/CoMoO$/ 4$ silica catalysts (d, e, and f).

As displayed in Figure 4, the TGA curve reveals that the CNTs begin to decompose at around $500^{\circ} \mathrm{C}$, which means that the catalyst is stable at the reaction temperature of $300^{\circ} \mathrm{C}$. This shows good thermal stability of the catalysts. There is about $45 \mathrm{wt} \%$ CNTs in the catalyst. The high percentage of CNTs offers large surface area for catalysts anchoring, leading to high and uniform catalysts dispersion, thus improving catalyst selectivity [26].

The GC-MS analytical results of the upgraded fuel samples are shown in Figure 5. Without catalysts, the target C8C16 carbon-chained molecules percentage is far lower than $5 \%$, except when looking at C15. In comparison, the two catalysts have obviously increased the target group of hydrocarbons with a different product range. $\mathrm{Pd} / \mathrm{CoMoO}_{4} /$ silica catalysts are inclusively effective on $\mathrm{C} 8, \mathrm{C} 14$, and $\mathrm{C} 16$, while $\mathrm{Pd} / \mathrm{CNTs} / \mathrm{CoMoO}_{4} / \mathrm{silica}$ shows a broad range of impact from $\mathrm{C} 10-\mathrm{C} 16$ with $\mathrm{C} 15$ as the most favorable product. Due to the short reaction time, few unsaturated hydrocarbons are observed (C14:1, C15:1, C16:1). We speculate that the selectivity shown in the two catalysts is originated from the different dispersion of metals in the two supports. For $\mathrm{Pd} / \mathrm{CoMoO}_{4} /$ silica, both $\mathrm{Pd}$ and $\mathrm{CoMoO}$ are loaded in mesopores of silica, where they are in close contact and can actively react with feedstock. For Pd/CNTs/CoMoO $4 /$ silica, 


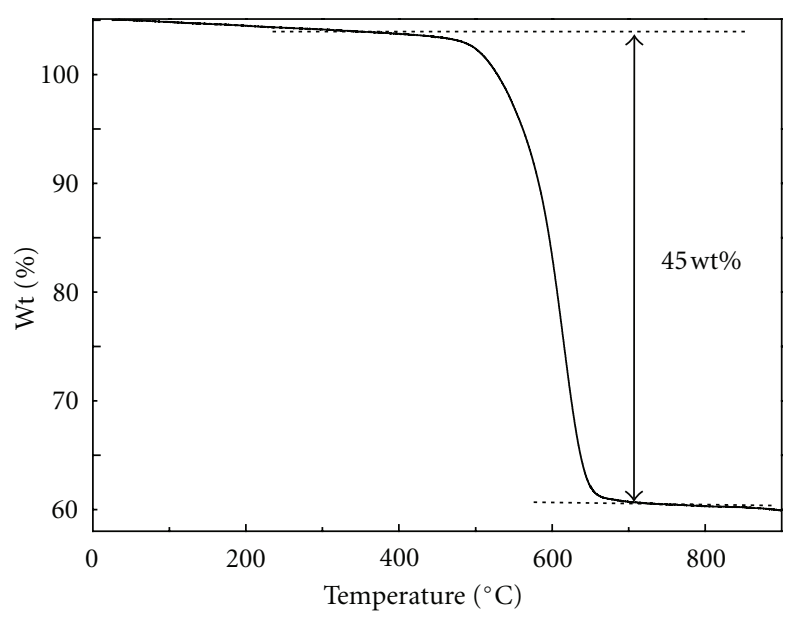

FIgure 4: TGA curve of Pd/CNTs/CoMoO$/$ /silica catalysts.

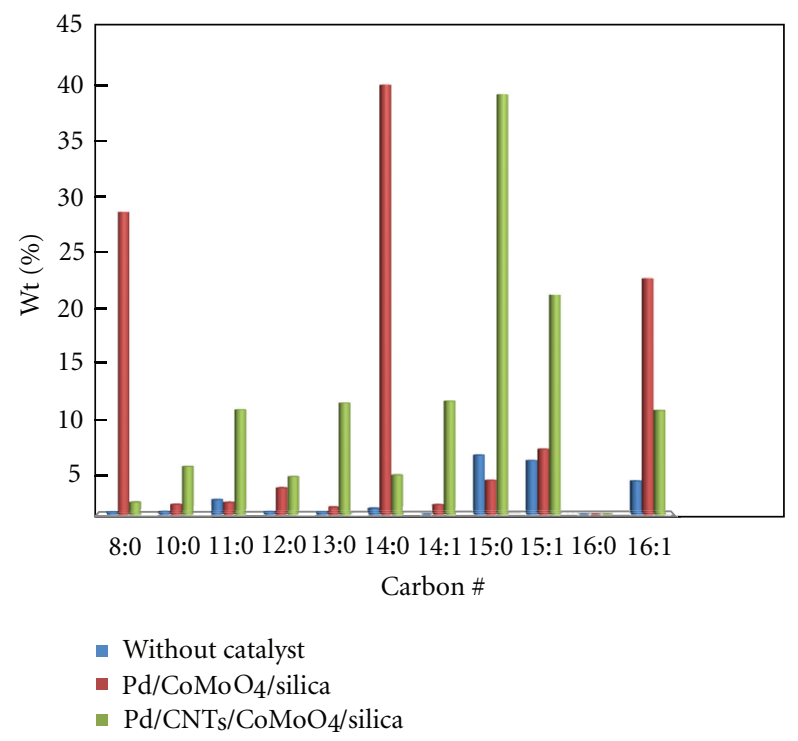

Figure 5: Hydrocracking performance of $\mathrm{Pd} / \mathrm{CoMoO}_{4} /$ silica and $\mathrm{Pd} / \mathrm{CNTs} / \mathrm{CoMoO}_{4} /$ silica: C8-C16 fraction before and after hydrocracking. $\mathrm{C}_{n: 0}$ indicates saturated hydrocarbons, and $\mathrm{C}_{n: 1}$ for the unsaturated ones.

Pd is loaded on the surface of the CNTs while $\mathrm{CoMoO}_{4}$ is loaded in the mesopores of silica. In this case, $\mathrm{Pd}$ and $\mathrm{CoMoO}_{4}$ are separated by the second support-CNTsand have a small chance to cooperate with each other. This separation is indicated by the extremely small BET surface area of $\mathrm{Pd} / \mathrm{CNTs} / \mathrm{CoMoO}_{4} /$ silica.

For $\mathrm{Pd} / \mathrm{CoMoO}_{4} /$ silica, the catalyst support is mesoporous silica. When $\mathrm{CoMoO}_{4}$ is loaded on silica, it may locate either on the surface of silica or in the pores of silica. The $\mathrm{CoMoO}_{4}$ coverage of pores in silica results in the decrease of BET surface area. As CNTs grow on $\mathrm{CoMoO}_{4}$ catalysts, CNTs further block the pores of silica. Therefore, it results in sharp decrease of BET surface area. Under this situation, the role of mesoporous silica is not significant for the hydrocracking reaction. However, it is still crucial for the structure and morphology of the catalysts. Because its mesopores offer space for $\mathrm{CoMoO}_{4}$, thus $\mathrm{CoMoO}_{4}$ can evenly load on the support and CNTs can grow on $\mathrm{CoMoO}_{4}$. If without silica, the $\mathrm{CoMoO}_{4}$ may aggregate together. Therefore, the selectivity of the $\mathrm{Pd} / \mathrm{CoMoO} /$ silica may be attributed to the synergic effect of $\mathrm{Pd}$ and $\mathrm{CoMoO}_{4}$, as $\mathrm{Pd} / \mathrm{CNTs} / \mathrm{CoMoO}_{4} /$ silica only has $\mathrm{Pd}$ as the active ingredient. Also, the reaction sites may have influence on the selectivity as well: one with reaction sites in mesopores of silica and the other with reaction sites on CNTs' surface.

\section{Conclusions}

Two nanocomposite catalysts, $\mathrm{Pd} / \mathrm{CoMoO}_{4} /$ silica and $\mathrm{Pd} /$ $\mathrm{CNTs} / \mathrm{CoMoO}_{4} / \mathrm{silica}$, were prepared and their catalytic performance was tested in the hydrocracking of camelina FAMEs. The catalyst supports played important roles in the catalytic process. Different support resulted in different selectivity of specific target groups due to synergism between metals and different reaction sites where the catalysts were loaded. Overall, the two catalysts both show high conversion and selectivity in a hydrocracking catalytic reaction. They are very promising and look to make a large impact in the application of biofuel upgrade.

\section{Acknowledgment}

The authors acknowledge the funding support from the Department of Defense, Air Force Research Laboratory, through contract FA8650-11-C-2127. They do not have a conflict of interest and do not have direct financial relation with the commercial identity mentioned in the paper.

\section{References}

[1] A. Srivastava and R. Prasad, "Triglycerides-based diesel fuels," Renewable \& Sustainable Energy Reviews, vol. 4, no. 2, pp. 111133, 2000.

[2] M. Snåre, I. Kubičková, P. Mäki-Arvela, K. Eränen, and D. Y. Murzin, "Heterogeneous catalytic deoxygenation of stearic acid for production of biodiesel," Industrial and Engineering Chemistry Research, vol. 45, no. 16, pp. 5708-5715, 2006.

[3] G. Knothe, "Biodiesel and renewable diesel: a comparison," Progress in Energy and Combustion Science, vol. 36, no. 3, pp. 364-373, 2010.

[4] G. W. Huber, S. Iborra, and A. Corma, "Synthesis of transportation fuels from biomass: chemistry, catalysts, and engineering," Chemical Reviews, vol. 106, no. 9, pp. 4044-4098, 2006.

[5] G. W. Huber and A. Corma, "Synergies between bio- and oil refineries for the production of fuels from biomass," Angewandte Chemie - International Edition, vol. 46, no. 38, pp. 7184-7201, 2007.

[6] E. W. Ping, R. Wallace, J. Pierson, T. F. Fuller, and C. W. Jones, "Highly dispersed palladium nanoparticles on ultra-porous silica mesocellular foam for the catalytic decarboxylation of stearic acid," Microporous and Mesoporous Materials, vol. 132, no. 1-2, pp. 174-180, 2010. 
[7] D. Kubička, P. Šimáček, and N. Žilkova, “Transformation of vegetable oils into hydrocarbons over mesoporous-aluminasupported CoMo catalysts," Topics in Catalysis, vol. 52, no. 1-2, pp. 161-168, 2009.

[8] P. Dufresne, P. H. Bigeard, and A. Billon, "New developments in hydrocracking: low pressure high-conversion hydrocracking.", Catalysis Today, vol. 1, no. 4, pp. 367-384, 1987.

[9] N. Ohshio, T. Enomoto, K. Honna et al., "Development of zeolite-based catalyst for resid hydrocracking," Fuel, vol. 83, no. 14-15, pp. 1895-1898, 2004.

[10] J. W. Ward, "Hydrocracking processes and catalysts," Fuel Processing Technology, vol. 35, no. 1-2, pp. 55-85, 1993.

[11] J. W. Scott and J. R. Kittrell, "Trends in the development of the modern hydrocracking process," Industial \& Engineering Chemistry, vol. 61, no. 7, pp. 18-22, 1969.

[12] S. Zhang, D. Liu, W. Deng, and G. Que, "A review of slurryphase hydrocracking heavy oil technology," Energy and Fuels, vol. 21, no. 6, pp. 3057-3062, 2007.

[13] L. Pellegrini, S. Bonomi, S. Gamba, V. Calemma, and D. Molinari, "The 'all components hydrocracking model'” Chemical Engineering Science, vol. 62, no. 18-20, pp. 5013-5020, 2007.

[14] B. Qiu, X. Yi, L. Lin, W. Fang, and H. Wan, "Influence of the incorporation of cobalt on non-sulfided Ni- $\mathrm{H}_{3} \mathrm{PW}_{12} \mathrm{O}_{40} / \mathrm{SiO}_{2}$ hydrocracking catalysts," Catalysis Communications, vol. 10, no. 9, pp. 1296-1299, 2009.

[15] A. M. Alsobaai, R. Zakaria, and B. H. Hameed, "Hydrocracking of petroleum gas oil over NiW/MCM-48-USY composite catalyst," Fuel Processing Technology, vol. 88, no. 9, pp. 921928, 2007.

[16] E. Benazzi, L. Leite, N. Marchal-George, H. Toulhoat, and P. Raybaud, "New insights into parameters controlling the selectivity in hydrocracking reactions," Journal of Catalysis, vol. 217, no. 2, pp. 376-387, 2003.

[17] M. A. Ali, T. Tatsumi, and T. Masuda, "Development of heavy oil hydrocracking catalysts using amorphous silica-alumina and zeolites as catalyst supports," Applied Catalysis A, vol. 233, no. 1-2, pp. 77-90, 2002.

[18] A. M. Stumbo, P. Grange, and B. Delmon, "Spillover hydrogen effect on amorphous hydrocracking catalysts," Catalysis Letters, vol. 31, no. 2-3, pp. 173-182, 1995.

[19] A. M. Alsobaai, R. Zakaria, and B. H. Hameed, "Gas oil hydrocracking on NiW/USY catalyst: effect of tungsten and nickel loading," Chemical Engineering Journal, vol. 132, no. 13, pp. 77-83, 2007.

[20] Y. Rezgui and M. Guemini, "Effect of acidity and metal content on the activity and product selectivity for n-decane hydroisomerization and hydrocracking over nickel-tungsten supported on silica-alumina catalysts," Applied Catalysis A, vol. 282, no. 1-2, pp. 45-53, 2005.

[21] I. Morawski and J. Mosio-Mosiewski, "Effects of parameters in Ni-Mo catalysed hydrocracking of vacuum residue on composition and quality of obtained products," Fuel Processing Technology, vol. 87, no. 7, pp. 659-669, 2006.

[22] W. S. Choi, K. H. Lee, K. Choi, and B. H. Ha, "Hydrocracking of vacuum gas oil on CoMo/alumina (or silica-alumina) containing zeolite," Studies in Surface Science and Catalysis, vol. 127, pp. 243-250, 1999.

[23] S. G. Jeon, J. Na, C. H. Ko, K. B. Yi, N. S. Rho, and S. B. Park, "Preparation and application of an oil-soluble CoMo bimetallic catalyst for the hydrocracking of oil sands bitumen," Energy \& Fuels, vol. 25, no. 10, pp. 4256-4260, 2011.

[24] J. Lee, S. Hwang, J. G. Seo, U. G. Hong, J. C. Jung, and I. K. Song, "Pd catalyst supported on $\mathrm{SiO}_{2}-\mathrm{Al}_{2} \mathrm{O}_{3}$ xerogel for hydrocracking of paraffin wax to middle distillate," Journal of
Industrial and Engineering Chemistry, vol. 17, no. 2, pp. 310315, 2011.

[25] K. M. Cho, S. Park, J. G. Seo et al., "Production of middle distillate in a dual-bed reactor from synthesis gas through wax cracking: effect of acid property of Pd-loaded solid acid catalysts on the wax conversion and middle distillate selectivity," Applied Catalysis B, vol. 83, no. 3-4, pp. 195-201, 2008.

[26] I. Nam, K. M. Cho, J. G. Seo, S. Hwang, K. W. Jun, and I. K. Song, "Production of middle distillate from synthesis gas in a dual-bed reactor through hydrocracking of wax over mesoporous $\mathrm{Pd}-\mathrm{Al}_{2} \mathrm{O}_{3}$ composite catalyst," Catalysis Letters, vol. 130, no. 1-2, pp. 192-197, 2009.

[27] K. M. Cho, S. Park, J. G. Seo et al., "Effect of calcination temperature of alumina supports on the wax hydrocracking performance of Pd-loaded mesoporous alumina xerogel catalysts for the production of middle distillate," Chemical Engineering Journal, vol. 146, no. 2, pp. 307-314, 2009.

[28] P. M. Ajayan and O. Z. Zhou, "Applications of carbon nanotubes," in Carbon Nanotubes Synthesis, Structure, Properties and Applications, M. S. Dresselhaus, G. Dresselhausand, and $\mathrm{Ph}$. Avouris, Eds., Springer, Berlin, Germany, 2001.

[29] H. Dai, "Carbon nanotubes: opportunities and challenges," Surface Science, vol. 500, no. 1-3, pp. 218-241, 2002.

[30] P. P. Zhang, X. X. Zhang, H. X. Sun, R. H. Liu, B. Wang, and Y. H. Lin, "Pd-CNT-catalyzed ligandless and additive-free heterogeneous Suzuki-Miyaura cross-coupling of arylbromides," Tetrahedron Letters, vol. 50, no. 31, pp. 4455-4458, 2009.

[31] X. Chen, Y. Hou, H. Wang, Y. Cao, and J. He, "Facile deposition of Pd nanoparticles on carbon nanotube microparticles and their catalytic activity for Suzuki coupling reactions," Journal of Physical Chemistry C, vol. 112, no. 22, pp. 81728176, 2008.

[32] W. E. Alvarez, B. Kitiyanan, A. Borgna, and D. E. Resasco, "Synergism of Co and Mo in the catalytic production of singlewall carbon nanotubes by decomposition of CO," Carbon, vol. 39, no. 4, pp. 547-558, 2001.

[33] V. M. Irurzun, Y. Tan, and D. E. Resasco, "Sol-gel synthesis and characterization of Co-Mo/silica catalysts for single-walled carbon nanotube production," Chemistry of Materials, vol. 21, no. 11, pp. 2238-2246, 2009.

[34] N. Bejenaru, C. Lancelot, P. Blanchard et al., "Synthesis, characterization, and catalytic performances of novel CoMo hydrodesulfurization catalysts supported on mesoporous aluminas," Chemistry of Materials, vol. 21, no. 3, pp. 522-533, 2009.

[35] Y. Fan, G. Shi, H. Liu, and X. Bao, "Selectivity enhancement of $\mathrm{Co}-\mathrm{Mo} / \mathrm{Al}_{2} \mathrm{O}_{3}$ FCC gasoline hydrodesulfurization catalysts via incorporation of mesoporous Si-SBA-15," Fuel, vol. 90, no. 5, pp. 1717-1722, 2011.

[36] Q. X. Jia, T. M. McCleskey, A. K. Burrell et al., "Polymerassisted deposition of metal-oxide films," Nature Materials, vol. 3, no. 8, pp. 529-532, 2004.

[37] Q. Lin, Y. Xu, E. Fu et al., "Polymer-assisted chemical solution approach to $\mathrm{YVO}_{4}: \mathrm{Eu}$ nanoparticle networks," Journal of Materials Chemistry, vol. 22, pp. 5835-5839, 2012.

[38] X. S. Shen, G. Z. Wang, X. Hong, and W. Zhu, "Shapecontrolled synthesis of palladium nanoparticles and their SPR/ SERS properties," Chinese Journal of Chemical Physics, vol. 22, no. 4, pp. 440-446, 2009. 

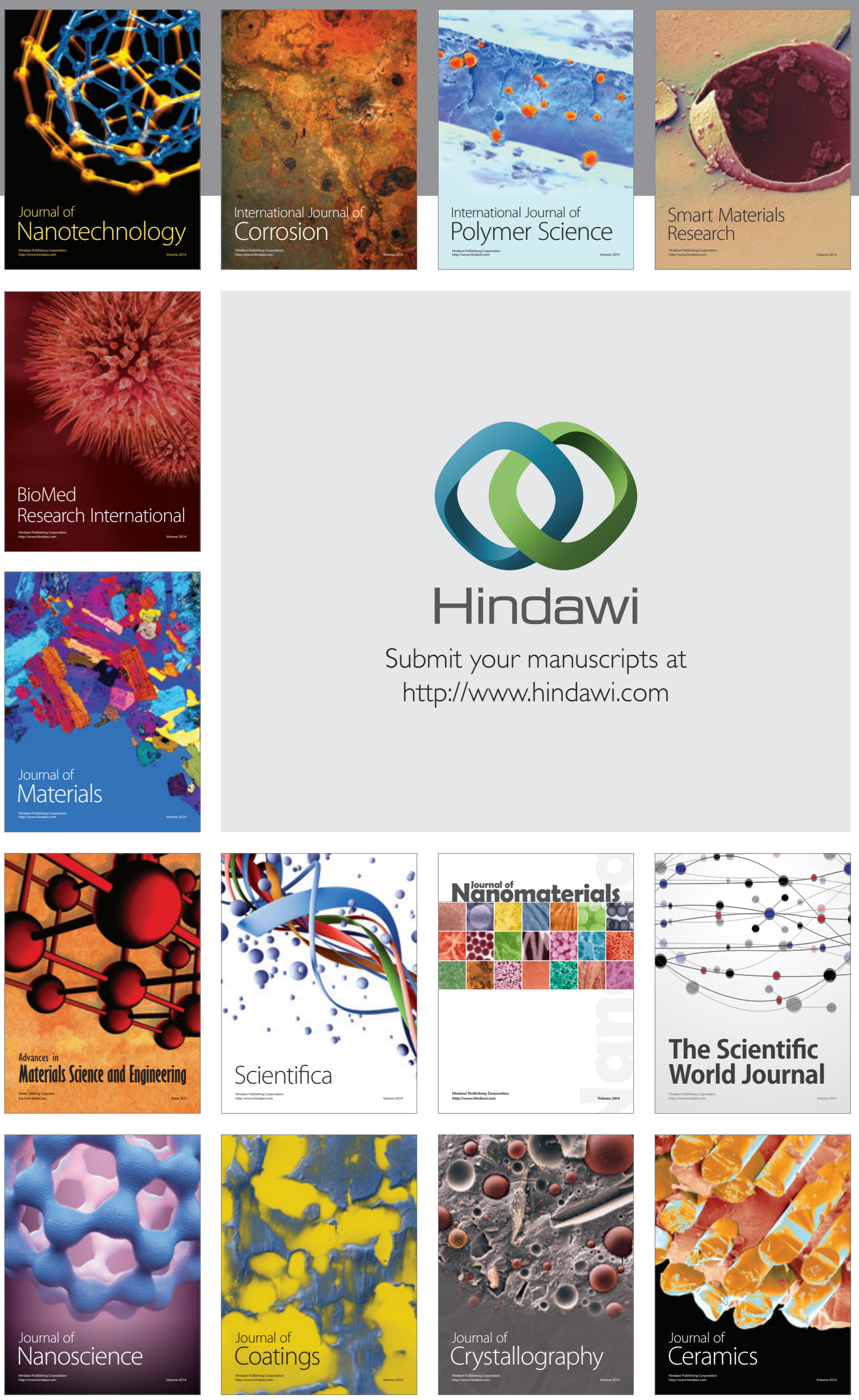

The Scientific World Journal

Submit your manuscripts at

http://www.hindawi.com

\section{World Journal}

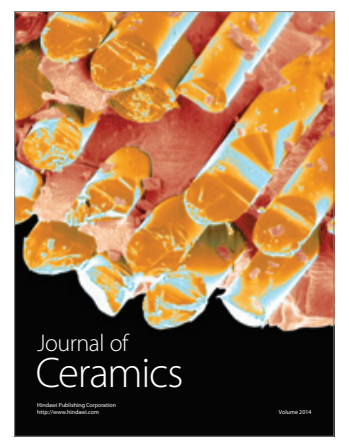


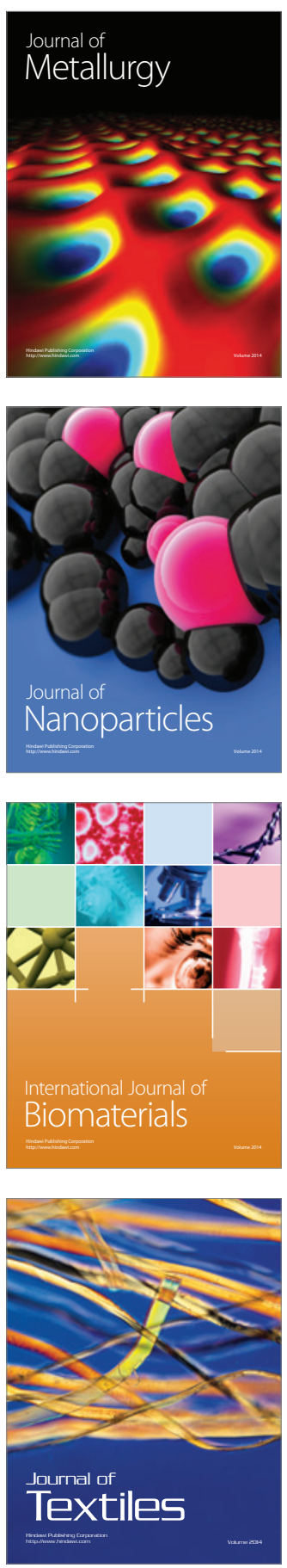